\title{
Ultrastructure of cell migration through the gastric epithelium and its relationship to bacteria
}

\author{
H. W. STEER ${ }^{1}$ \\ From Southampton University Medical School
}

SYNOPSIS The migration of polymorphonuclear leucocytes and lymphocytes through the gastric mucosa has been studied with the electron microscope. Bacteria have been found related to the gastric epithelium. Arguments in favour of these bacteria not being contaminants at the time that the biopsies were taken are presented. The relationship between polymorphonuclear leucocyte migration and the occurrence of bacteria is discussed.

Gastritis is an ill-understood histopathological entity. This may be readily deduced from the numerous attempts to create a meaningful classification of the types and grades of gastritis. Despite the relative lack of knowledge as to its precise aetiology, which is probably multifactorial, histopathologists have made detailed analyses of its occurrence, and of its relationship to the various kinds of gastroduodenal pathology. Debate has also centred upon its relationship to the aetiology of peptic ulceration (Gear, Truelove, and Whitehead, 1971; Hebbel, 1943; Hebbel, 1949; Magnus, 1946; Palmer, 1954; Schindler, 1947).

That the gastric epithelium is a dynamic tissue has been revealed by autoradiographic studies using tritiated thymidine (Creamer, Shorter, and Bamforth, 1961; MacDonald, Trier, and Everett, 1964). This dynamic state persists in pathological tissue and is readily illustrated by the activity of the gastritis' (Gear et al, 1971) when the gastric epithelium is invaded by migrating polymorphonuclear leucocytes and lymphocytes.

The present study of the ultrastructure of the cells migrating through the gastric epithelium was undertaken in order to determine whether any information could be obtained concerning the aetiology of this migration.

\section{Material and Methods}

Gastric biopsies were obtained from eight patients at operation for gastric ulceration. Tissue was also

${ }^{1}$ Present address: Southampton General Hospital

Received for publication 6 February 1975. obtained at gastroscopy from 39 patients suffering from gastric ulceration; in these cases biopsies were taken from the prepyloric region, the incisura angularis, high on the lesser curve, high on the greater curve, and at the edge of the ulcer. The tissues were immediately fixed in cacodylate buffered $5 \%$ glutaraldehyde (pH 7.3) for four hours at $4{ }^{\circ} \mathrm{C}$. They were subsequently washed in cacodylate buffered $10 \%$ sucrose solution for 24 hours and were then postfixed in veronal acetate buffered $1 \%$ osmium tetroxide ( $\mathrm{pH} \mathrm{7.3)}$ for one hour at $4{ }^{\circ} \mathrm{C}$, rinsed in chilled tap water and chilled $70 \%$ ethyl alcohol at $4{ }^{\circ} \mathrm{C}$, and dehydrated in a graded series of ethyl alcohol solutions; propylene oxide was used as the clearing agent. The cleared tissues were embedded in Araldite.

Sections $1 \mu \mathrm{m}$ thick were cut with a glass knife on an ultramicrotome and stained by the method of Richardson, Jarrett, and Fincke (1960). These sections were examined with a light microscope and, as a result, certain limited areas were selected from which sections approximately $25 \mathrm{~nm}$ were cut with a glass knife. These were stained with $1 \%$ uranyl acetate and Reynold's lead citrate, and examined with a Philips 300 electron microscope.

\section{Results}

MIGRATION OF POLYMOR PHONUCLEAR

LEUCOCYTES

Polymorphonuclear leucocytes migrate from blood capillaries in the gastric mucosa through the gastric epithelium into the gastric lumen (fig 1). The polymorphonuclear leucocytes are frequently located at the periphery of the capillaries and are often 


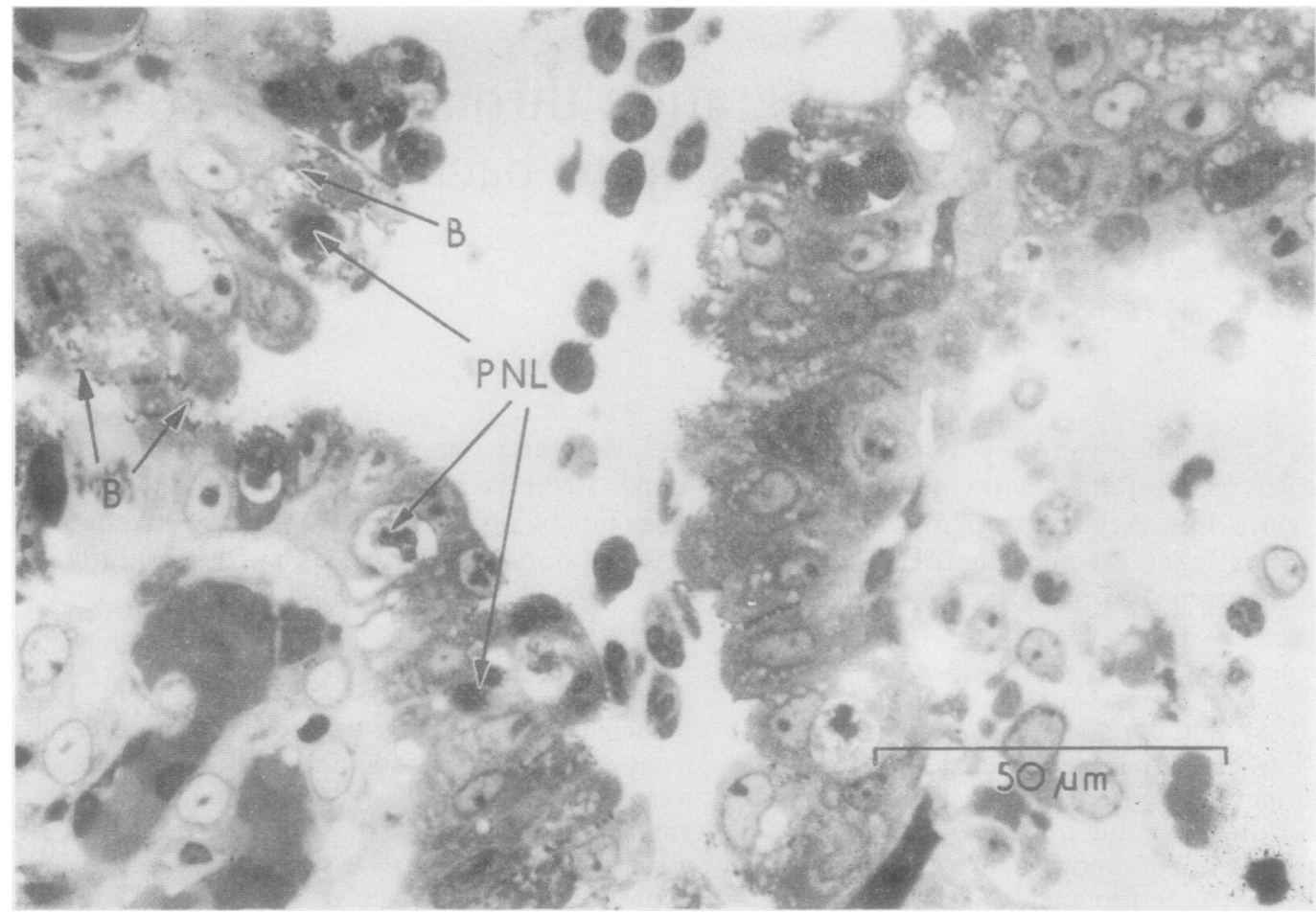

Fig 1 The gastric mucosa in the region of the gastric pits. Polymorphonuclear leucocytes (PNL) are migrating through the gastric epithelium. Bacteria (B) are related to the luminal aspect of these epithelial cells.

associated with strands of fibrin in the blood vessel. They pass through the endothelial lining of the blood vessel (fig 2) and become interposed between the endothelium and its surrounding basement lamina. The migrating polymorphonuclear leucocytes traverse the endothelial basement lamina and reach the gastric epithelium by passing through the mucosal connective tissue. They enter the gastric epithelium by passing through the underlying basement lamina (fig 3 ) and pass through the epithelium along the intercellular spaces. Ultimately the polymorphonuclear leucocytes are shed into the gastric lumen (fig 4) but in order for them to do so the zona occludens and zona adherens must be breached. No junctional complexes are observed between the gastric epithelial cells and the migrating polymorphonuclear leucocytes.

\section{MIGRATION OF LYMPOCYTES}

The gastric mucosa contains numerous lymphoid follicles. Small lymphocytes migrate from these follicles through the mucosal connective tissue, traversing the underlying basal lamina to enter the gastric epithelium. The lymphocytes lie between the epithelial cells (fig 5) and migrate through the epithelium into the gastric lumen.

\section{BACTERIA AND THE GASTRIC MUCOSA}

Bacteria are frequently related to the gastric epithelium (figs 1 and 6). They are usually apposed to the mucus-secreting cells although occasional bacteria are related to other epithelial cells, for example, oxyntic cells. The bacteria possess typical outer and inner double membranes. The external layer of the outer membrane is more electron dense than the remaining layers, and at certain places the internal layer of the outer membrane is connected to the external layer of the inner membrane. The membranes bound the granular content of the bacteria; the granules, about $1 \mathrm{~nm}$ in diameter, are unevenly distributed throughout the bacterium. At least one filum projects from one end of the bacterium.

Bacteria are often seen in clusters and individual bacteria come into close apposition with the epithelial cells, the interval between the bacterium and the surface membrane being filled with a material which represents the glycocalyx of the 


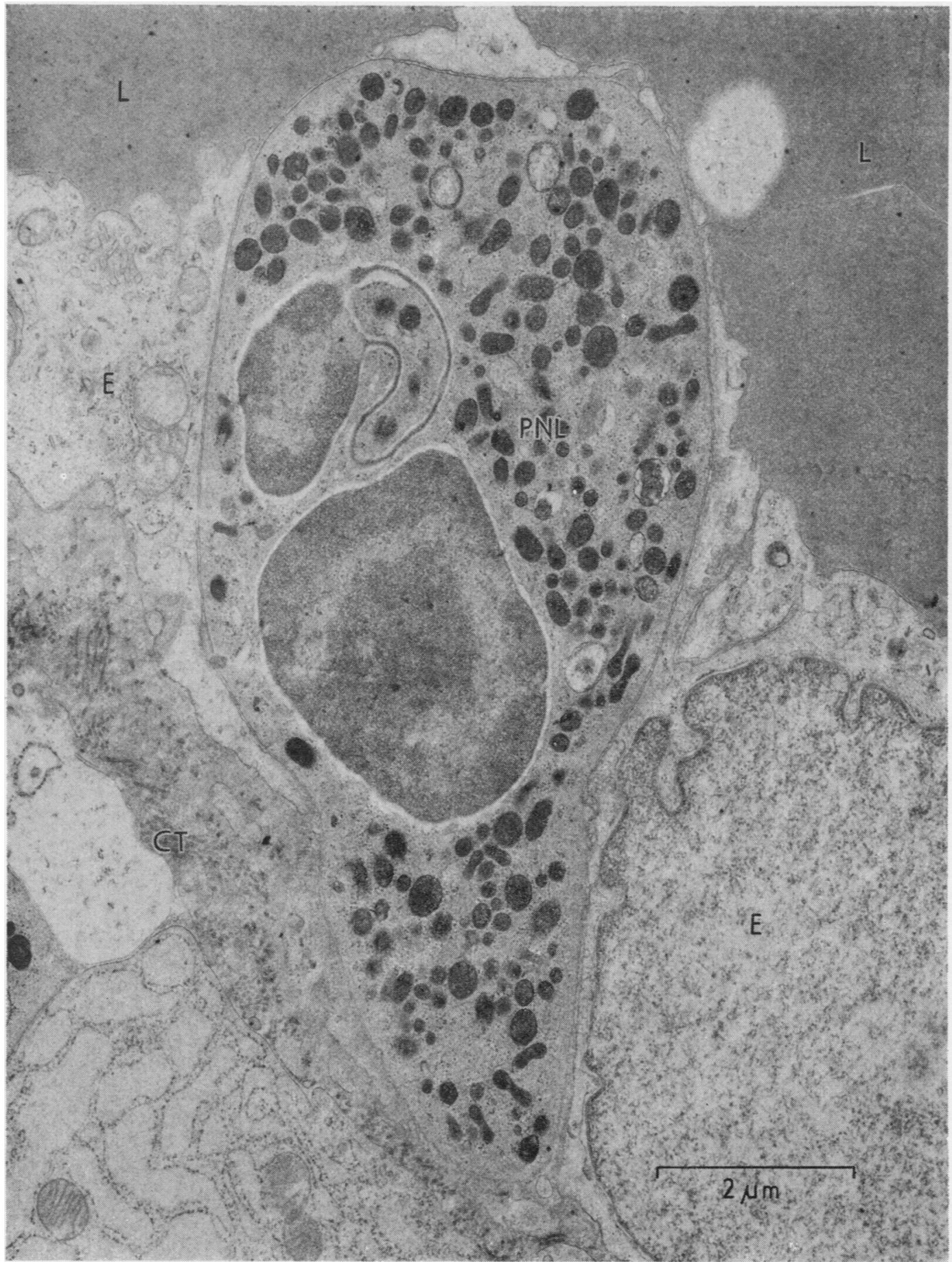

Fig 2 A polymorphonuclear leucocyte (PNL) is migrating from the blood vessel lumen (L) through its endothelium (E) into the surrounding connective tissues (CT). 


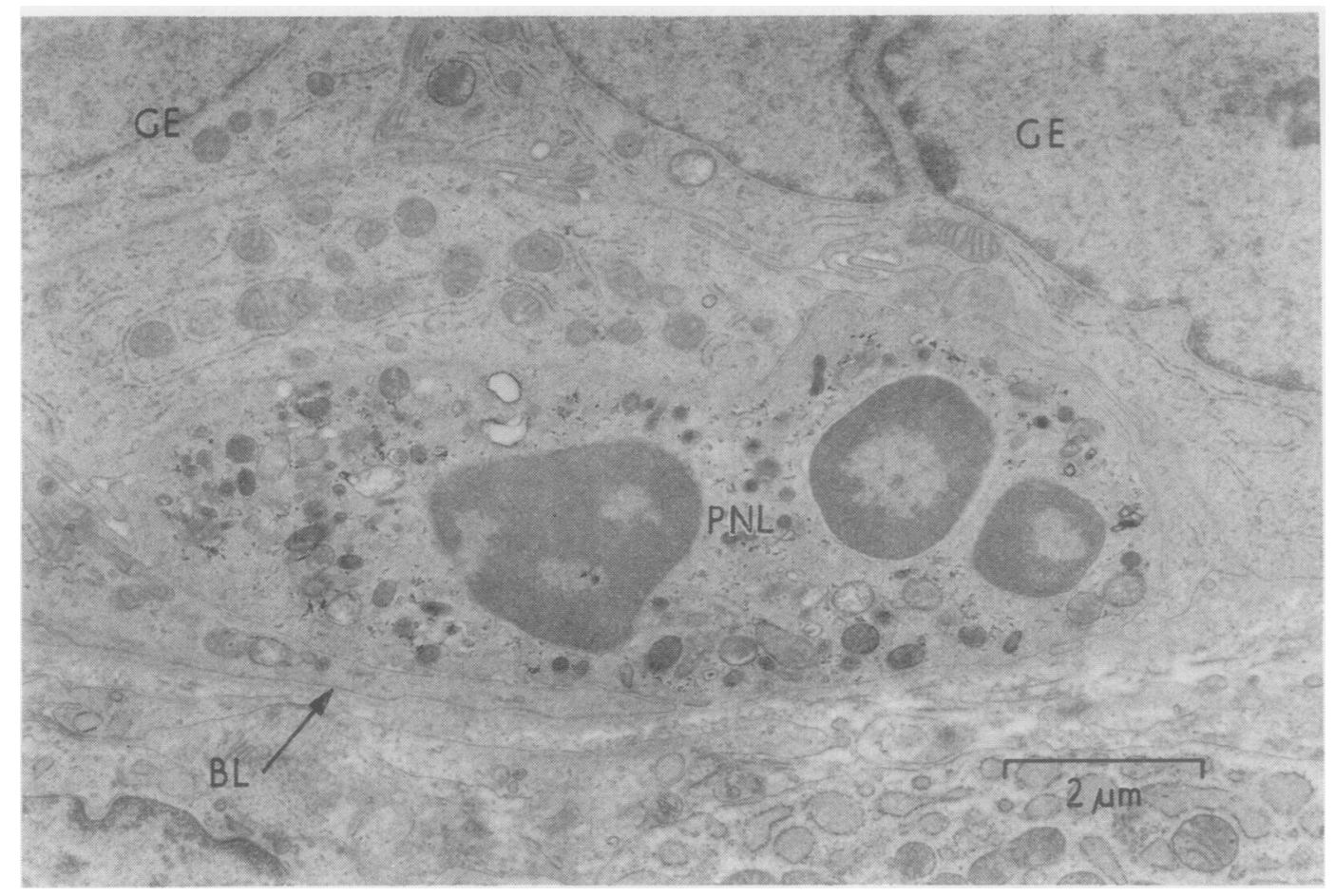

Fig 3 A polymorphonuclear leucocyte (PNL) is seen lying between the gastric epithelial cells (GE) and the basement lamina (BL) of this epithelium.

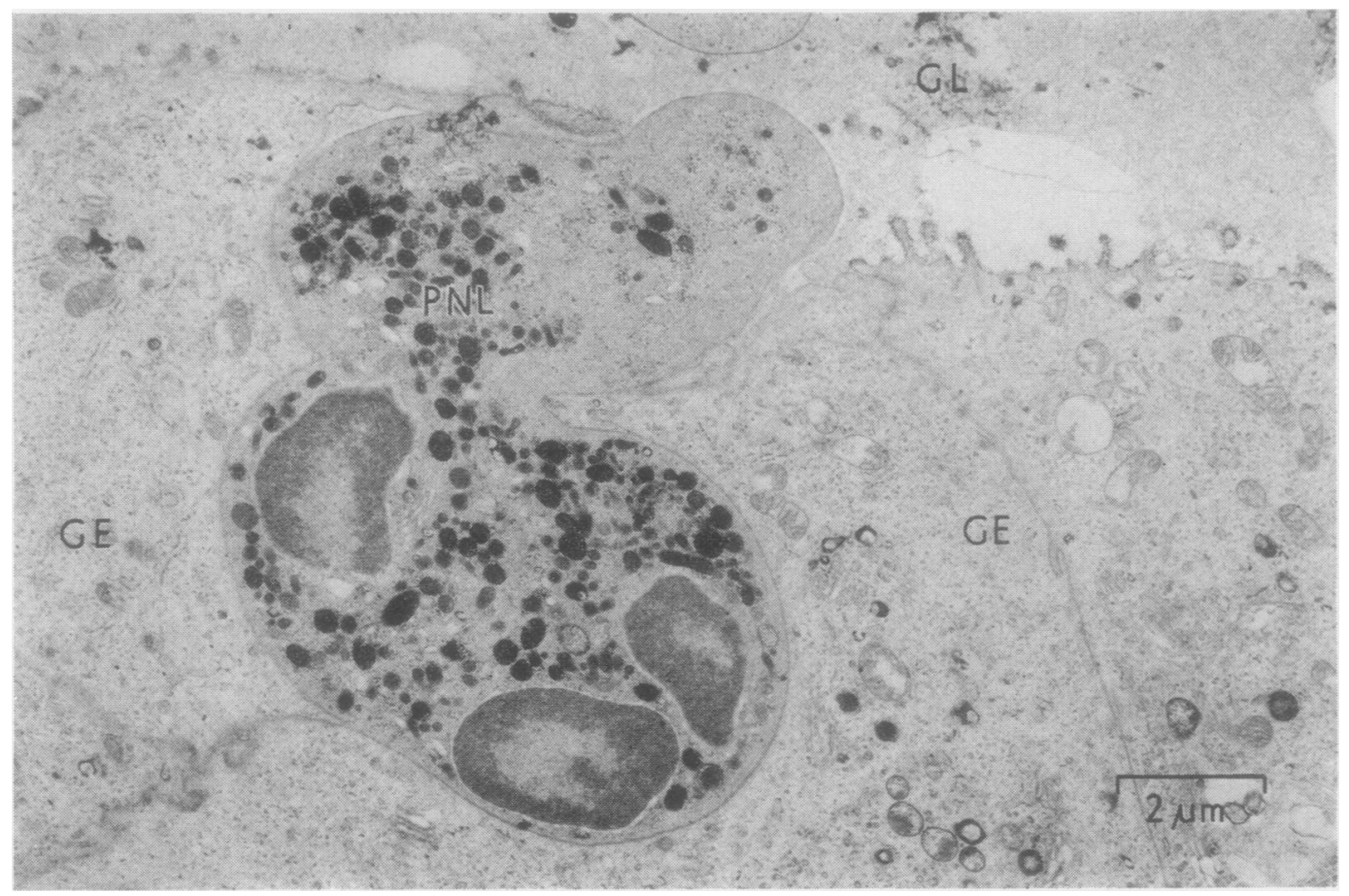

Fig 4 A polymorphonuclear leucocyte (PNL) is being shed from the gastric epithelium (GE) into the gastric lumen. 


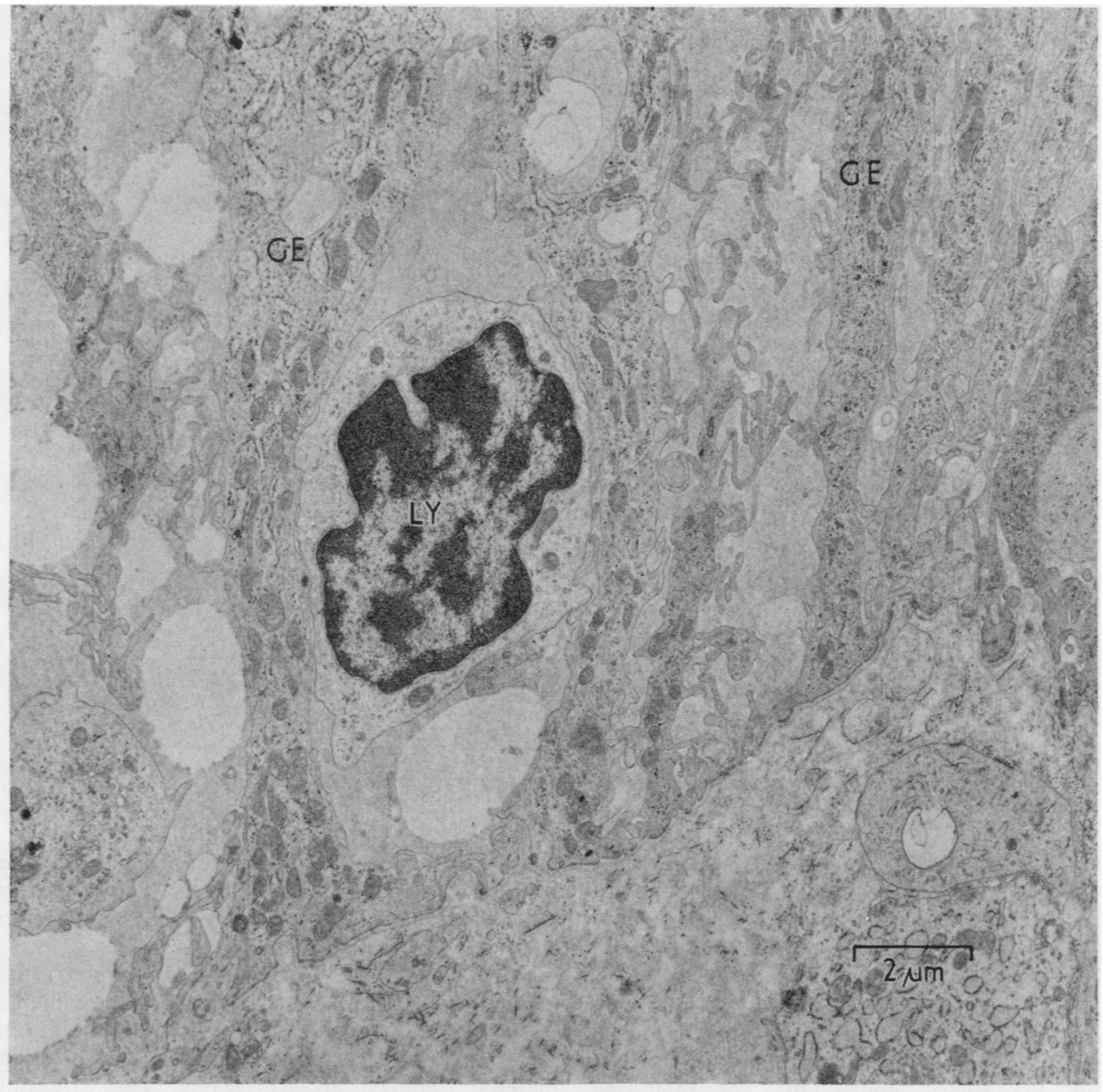

Fig 5 A lymphocyte (LY) is seen in an intercellular space of the gastric epithelium.

epithelial cell and the amorphous material surrounding a bacterium. Some bacteria are separated from the epithelial cells by an interval of only $1 \mathrm{~nm}$.

Migrating polymorphonuclear leucocytes are also seen in the epithelium which is apposed to the bacteria, but this relationship is not constant: numerous migrating polymorphonuclear leucocytes are also seen in epithelium which is unrelated to any bacteria. Some polymorphonuclear leucocytes which have migrated into the gastric lumen contain phagocytosed bacteria (fig 7) which have similar ultrastructural characteristics to the bacteria which are related directly to the gastric epithelium. The bacteria in polymorphonuclear leucocytes are situated within membrane bound vesicles which are continuous with the generalized membrane system of the polymorphonuclear leucocyte. In addition to the bacterium, the vesicles contain electron dense granules, $\mathrm{ca} 2 \mathrm{~nm}$ diameter, and these granules are found irregularly distributed in the cytoplasm of the polymorphonuclear leucocyte.

\section{Discussion}

The migration of polymorphonuclear leucocytes and lymphocytes through the gastric mucosa and 


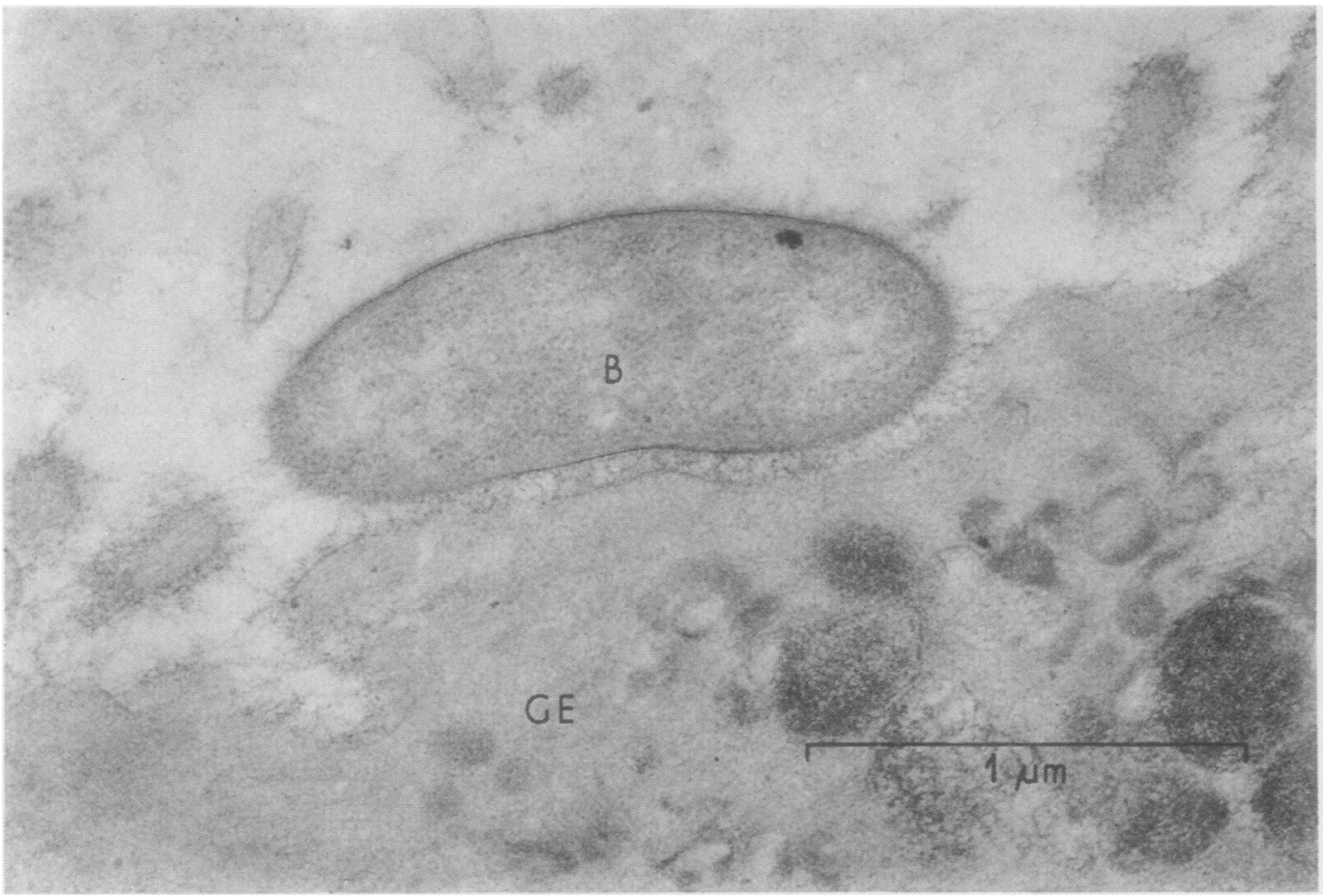

Fig 6 A bacterium (B) is apposed to a mucus secreting cell of the gastric epithelium (GE).

into the gastric lumen is an active process, the cells passing from blood vessels and lymphoid follicles in the subepithelial regions. The tissue boundaries are no barrier to the migration of these cells from tissue of mesodermal origin through tissue of endodermal origin. During this migration the junctional complexes between adjacent epithelial cells do not appear to hinder the transit of the cells through the gastric epithelium. The migrating cells do not form any specialized junctions with the cells of the tissue through which they are migrating.

In the normal stomach there are no migrating polymorphonuclear leucocytes but some lymphocytes are found in the gastric epithelium (Steer and Colin Jones, 1975). However, in certain pathological states there is a considerable migration of polymorphonuclear leucocytes and lymphocytes, and these migrating cells do not appear to be ultrastructurally degenerate. Although the tissue containing migrating polymorphonuclear leucocytes is pathological, it is nevertheless viable and does not appear to be necrotic. The observation of Gear et al (1971) that the acute inflammatory cells are destroying the surface epithelium has not been substantiated. The polymorphonuclear leucocytes appear to be migrating in response to some extrinsic factor or factors. The present study suggests the identity of one such factor. Bacteria are frequently related to the gastric epithelium and come into close association with its surface.

There is considerable evidence to support the contention that these bacteria are not contaminants introduced at the time of biopsy. They are found in material obtained at open operation as well as in material obtained at gastroscopy. They are not universally present in all specimens and are not invariably seen in all specimens obtained from an individual patient. The bacteria are related only to the epithelial surface of the biopsies whereas if they were contaminants of the biopsy forceps they would also be distributed on the non-epithelial surface of the biopsy. At the epithelial surface the bacteria are situated deep to the layer of mucus covering the gastric surface, whereas if they were contaminants they would be situated on the superficial aspect of this layer. The bacteria also form definite relationships with the gastric epithelial cells, and some have been phagocytosed by polymorphonuclear leucocytes which have migrated into the gastric lumen. If the bacteria were contaminants this would not have occurred because the tissue is immediately placed into fixative. 


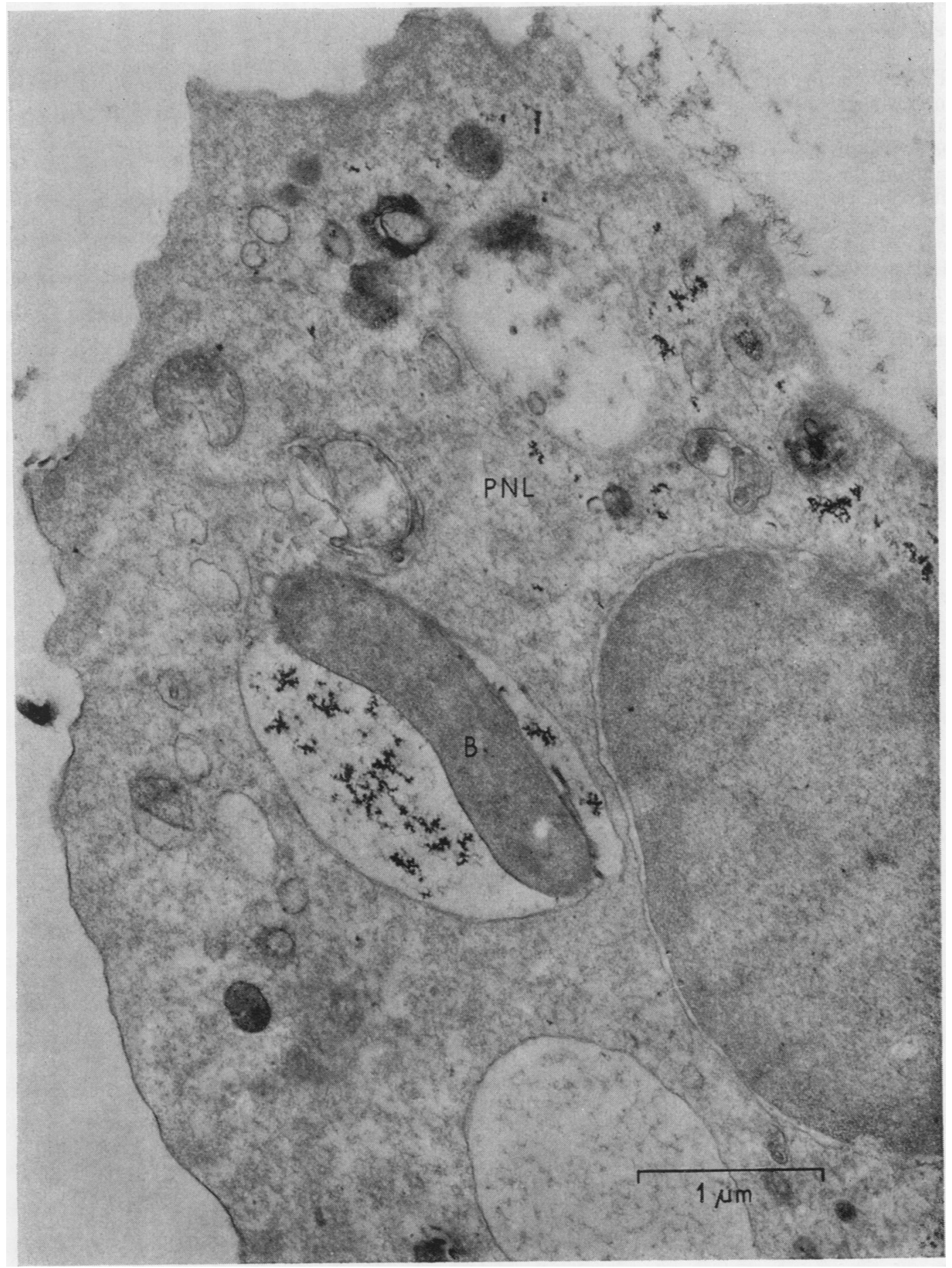

Fig 7 A polymorphonuclear leucocyte (PNL) is lying in the gastric lumen. A bacterium (B) has been phagocytosed by this cell. 
Bacteriological studies have identified the bacteria as Pseudomonas aeruginosa (Steer and Colin Jones, 1975).

The migration of polymorphonuclear leucocytes is not entirely a response to the bacteria related to the gastric epithelium and has been observed in the absence of any bacteria. It would therefore appear that although bacteria may be one factor causing polymorphonuclear leucocyte migration there must be other factors involved. This investigation, which has not included any immunological study, has failed to reveal any obvious aetiological factors for the lymphocytic migration.

I gratefully acknowledge the encouragement and facilities afforded to me by Professor D. Bulmer. I am indebted to Dr D. G. Colin Jones and $\mathrm{Mr}$ B. J. Wilken for allowing me to study patients under their care, to Mr B. Backhouse and Mrs L. Baker for technical assistance, and to Mrs J. Steer for secretarial help.

\section{References}

Creamer, B., Shorter, R. G., and Bamforth, J. (1961). The turnover and shedding of epithelial cells. Part $I$. The turnover in the gastro-intestinal tract. Gut, 2, 110-116.

Gear, M. W. L., Truelove, S. C., and Whitehead, R. (1971). Gastric ulcer and gastritis. Gut, 12, 639-645.

Hebbel, R. (1943). Chronic gastritis: its relation to gastric and duodenal ulcer and to gastric carcinoma. Amer. J. Path., 19, 43-71.

MacDonald, W. C., Trier, J. S., and Everett, N. B. (1964). $\vec{\circ}$ Cell proliferation and migration in the stomach, duodenum, and rectum of man: radioautographic studies. Gastroenterology, 46, 405-417.

Magnus, H. A. (1946). The pathology of simple gastritis. J. Path. Bact., 58, 431-439.

Palmer, E. D. (1954). Gastritis: a revaluation. Medicine N (Baltimore), 33, 199-290.

Richardson, K. C., Jarrett, L., and Fincke, E. H. (1960). Embedding in epoxy resins for ultrathin sectioning in electron microscopy. Stain Technol., 35, 313-323.

Schindler, R. (1947). Gastritis. Heinemann, London. Grune and Stratton, New York.

Steer, H. W. and Colin Jones, D. (1975). In preparation. 